\title{
ERROS EM RECEITAS DE CONTROLE ESPECIAL E NOTIFICAÇÕES DE RECEITA PRESCRITAS POR PROFISSIONAIS NÃO MÉDICOS
}

\author{
ERRORS IN SPECIAL CONTROL PRESCRIPTION AND PRESCRIPTION NOTIFICATION DONE BY \\ NON-MEDICAL PROFESSIONALS
}

\author{
Rebeca Santos Cardoso ${ }^{a^{*}}$, Ionara Vieira Rocha da Mota ${ }^{b^{*}}$, Lucas Brasileiro Lemos ${ }^{c^{*}}$, \\ Paulo Henrique Ribeiro Fernandes Almeida ${ }^{\mathrm{d}^{* *}}$, Mário Borges $\operatorname{Rosa}^{\mathrm{e}^{* * *}}$, \\ Gisele da Silveira Lemos ${ }^{* *}$

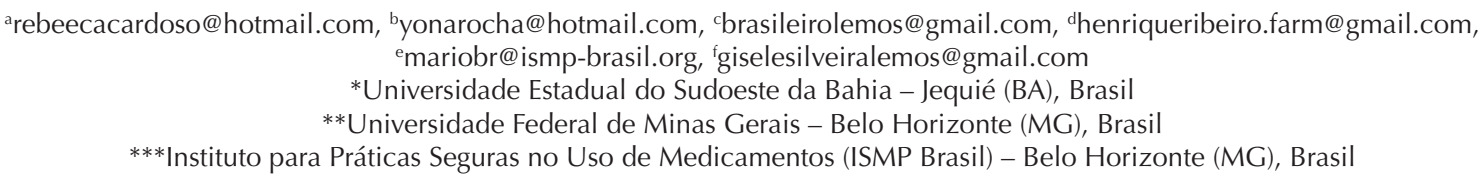

Data de recebimento do artigo: 25/09/2017 Data de aceite do artigo: 18/10/2017

\section{RESUMO}

Introdução: Cirurgiốes dentistas e médicos-veterinários são legalmente habilitados a prescrever medicamentos sob controle especial com indicação dentro de suas áreas de atuação. No entanto, existe uma lacuna de estudos que descrevam a completude de prescriçốes realizadas por profissionais não médicos conforme legislaçôes, normas sanitárias e éticas estabelecidas no Brasil. Objetivo: Avaliar erros de prescriçâo em notificaçôes de receita e receitas brancas de medicamentos sujeitos a controle especial pela Portaria 344/1998, as quais tenham sido realizadas por profissionais não médicos, cirurgióes-dentistas e médicos-veterinários. Metodologia: Estudo transversal, realizado com base em análise documental de prescriçôes arquivadas em uma farmácia comunitária de um município no estado da Bahia, com aplicação de um formulário padronizado. Os softwares EpiData 3.1 e SPSS 21.0 auxiliaram na tabulação e análise dos dados, descritos em frequência absoluta e relativa e com média e desvio padrão. O nível de significância adotado foi 5\%. Resultados: Foram analisadas 235 prescriçóes, das quais $67,7 \%$ (159) foram realizadas por cirurgióes-dentistas e 32,3\% (76) por médicos-veterinários. A associação paracetamol com codeína predominou em $69,8 \%$ das receitas de cirurgióes-dentistas, e os antiepilépticos prevaleceram em $75 \%$ das receitas de médicos-veterinários. Houve um total de 1.529 erros de prescrição entre médicos-veterinários e cirurgiôes-dentistas, com média superior para os médicos-veterinários. Conclusão: Realizar prescriçốes com dados completos evita erros e promove uma adequada e segura terapêutica para a populaçấo usuária.

Palavras-chave: Prescrição de medicamentos; erros de medicação; odontólogos; médicos-veterinários.

\section{ABSTRACT}

Introduction: Dental surgeons and veterinary doctors are legally entitled to prescribe drugs under special control with indication within their areas of practice. However, there is a gap in studies that describe the completeness of prescriptions performed by non-medical professionals according to laws and health and ethical standards established in Brazil. Objective: To evaluate errors in prescription notifications and white prescriptions of drugs subject to special control by Portaria 344/1998, which have been performed by non-medical professionals, dental surgeons, and veterinarians. Methodology: A cross-sectional study, based on documentary analysis of prescriptions that were filed in a community pharmacy from a municipality in the state of Bahia, with the application of a standardized form. The EpiData 3.1 and SPSS 21.0 software helped to tabulate and analyze the data, described in absolute and relative frequency and with mean and standard deviation of significance level $\mathrm{p}<0.05$. Results: A total of 235 prescriptions of which $67.7 \%$ (159) were done by dental surgeons and $32.3 \%$ (76) by veterinarians were analyzed. The association paracetamol with codeine predominated in $69.8 \%$ of the revenues of dentists, and antiepileptics prevailed in $75 \%$ of the recipes of veterinarians. There was a total of 1,529 prescribing errors among 
veterinary surgeons and dentists, and veterinarians had a higher average. Conclusion: To make prescriptions with complete data is the best way to avoid errors and to promote an adequate and safe therapeutics for the user population.

Keywords: Drug prescription; medication errors; dentists; veterinarians.

\section{Introdução}

Os medicamentos são instrumentos terapêuticos que auxiliam na recuperação da saúde e na garantia da qualidade de vida, contribuindo para o tratamento e profilaxia de diversas patologias, além de retardar o surgimento de complicaçóes relacionadas com as enfermidades ${ }^{1}$. Contudo, apesar dos seus benefícios, eles não são isentos de riscos, sendo seu uso irracional um problema de saúde pública. Desse modo, a utilização de medicamentos e o acesso à assistência médica não garantem melhores condiçôes de saúde, uma vez que hábitos inadequados de prescrição, erros de medicação e o uso inapropriado de medicamentos podem levar a uma terapêutica inefetiva e pouco segura ${ }^{2}$.

A Política Nacional de Medicamentos (PNM) define a prescrição como uma ação que estabelece a intervenção medicamentosa proposta pelo profissional legalmente habilitado (médico, dentista ou veterinário) e destinada ao paciente ou animal, com informaçôes apropriadas sobre os fármacos prescritos, como dose e duração do tratamento. Esse ato é sintetizado em uma receita, acrescida de orientaçôes para utilização dos medicamentos prescritos ${ }^{3}$, sendo o principal meio de comunicação entre prescritores, enfermeiros, farmacêuticos e pacientes/cuidadores, e por ser um documento legal, deve ser elaborado de acordo com padrôes e normas estabelecidas pela legislação brasileira específica ${ }^{4}$.

Entre as inúmeras medidas que ensejam promover o uso racional de medicamentos estão as de cunho regulador aplicáveis a comércio, importaçâo, uso, dispensação e prescrição de medicamentos sob controle especial ${ }^{5,6}$, as quais, quando realizadas de maneira adequada, podem tornar o tratamento terapêutico mais efetivo. A deficiência da atenção reguladora, no que diz respeito à prescrição e dispensação desses medicamentos, pode proporcionar a ocorrência dos erros de medicação, resultando em aumento dos riscos frente aos benefícios da terapia para o consumidor ${ }^{7,8}$.

Estudos comprovam que inconformidades nas prescriçóes podem ocasionar interpretaçóes incorretas, principalmente quando as receitas se encontram ilegíveis ou incompletas, com falha na padronização da nomenclatura dos medicamentos prescritos, com uso de abreviaturas e ainda com rasuras ${ }^{4,9}$.
No Brasil a norma vigente para a regulação de medicamentos sob controle especial (psicoativos) é a Portaria de $\mathrm{n}^{\circ} 344$, de 12 de maio de 1998, do Ministério da Saúde ${ }^{3}$, que se propóe a inibir o comércio ilegal, o desvio de uso e o abuso desses fármacos, além de estabelecer parâmetros para a prescrição, venda e dispensação dessas substâncias ${ }^{7}$. Esse controle é realizado pela padronização de modelos de receitas específicas conforme as listas: A1 e A2 (entorpecentes), A3, B1 e B2 (psicotrópicas), C1 (outras substâncias sujeitas a controle especial), C2 (retinóicas para uso sistêmico) e C3 (imunossupressoras), C4 (antirretrovirais) e C5 (anabolizantes) ${ }^{3}$.

A prescrição adequada desses fármacos por profissionais não médicos, legalmente habilitados, com indicação para as especialidades dentro do âmbito de cada profissão (cirurgiâo dentista e médico-veterinário), juntamente à completude legal das receitas, favorece a qualidade na dispensaçáo e utilização do medicamento, criando condiçóes a um uso racional e não abusivo dessas substâncias, porém o sistema que regulamenta o controle de prescriçóes, dispensação e utilização pode não ser eficiente ${ }^{3,4,7,10,11}$.

Nesse sentido, diante da lacuna de estudos que evidenciam o conhecimento sobre as normas prescricionais vigentes no Brasil, avaliou-se as notificações de receita e receitas de controle especial prescritas por profissionais não médicos (cirurgiōes-dentistas e médicos-veterinários).

\section{Metodologia}

Estudo transversal realizado com base em análise documental de receitas de controle especial e notificaçóes de receita das listas A e B1 da Portaria no 344/98 SVS/MS ${ }^{3}$ prescritas por profissionais não médicos (cirurgiōes-dentistas e médicos-veterinários) em arquivo de uma farmácia comunitária, pertencente a uma rede de farmácias de âmbito nacional e situada em um município da região sudoeste do estado da Bahia.

A farmácia comunitária na qual foi realizado o estudo funciona das $7 \mathrm{~h}$ às $22 \mathrm{~h}$, de segunda-feira a sábado, e das $8 \mathrm{~h}$ às $20 \mathrm{~h}$, aos domingos e feriados, com uma equipe de trabalho composta por um gerente, três farmacêuticos (um em cada turno), oito 
auxiliares de balcáo, sete auxiliares de caixa, quatro funcionários do administrativo e um funcionário para serviços gerais.

Os dados dessa pesquisa foram coletados utilizando todas as receitas de controle especial e notificaçôes de receitas odontológicas e veterinárias arquivadas em um período de 25 meses (de $1^{\circ}$ de junho de 2014 a 30 de junho de 2016). Os dados dessas prescriçôes foram compilados em um formulário para análise de conteúdo das notificaçóes de receitas médicas contendo 33 variáveis. Os dados da prescrição de controle especial de duas vias e das notificaçóes de receita foram subdivididos em: da prescriçáo, do paciente, do prescritor e do medicamento, segundo os dispositivos legais da Portaria SVS/MS 344/98.

Foi realizado o levantamento da frequência absoluta dos fármacos prescritos por cada classe de profissional não médico estudada, e agrupadas conforme a classificação Anatomical Therapeutic Chemical (ATC) - desenvolvida pelo WHO Collaborating Centre for Drug Statistics Methodology (Centro Colaborador de Metodologias Estatísticas de Medicamentos da Organização Mundial de Saúde) -, na qual os medicamentos são classificados em grupos e subgrupos, obedecendo a cinco níveis de acordo com os órgáos e sistemas de atuaçóes, bem como suas propriedades químicas, terapêuticas e farmacológicas.

Os dados foram agrupados utilizando o software Epidata 3.1 (EpiData Association, Odense, Dinamarca) como banco de dados, sendo posteriormente analisados pelo software SPSS 21.0 (IBM Corporation, Armonk, Estados Unidos). Para as variáveis independentes e dependentes, foi utilizada a estatística descritiva, determinando as medidas do centro da distribuição e medidas da variabilidade, as medidas da variabilidade para a variável quantitativa, além das frequências absolutas e relativas para as variáveis qualitativas. A variável quantitativa de erros de prescrição foi descrita com média e desvio padrão (DP) com intervalo de confiança de 95\% (IC95\%). Para verificar os parâmetros de normalidade foi aplicado o teste Kolmogorov-Smirnov nas frequências relativas e absolutas nos dados de prescrição. Para verificar a existência de associação entre variáveis de cirurgiôes-dentistas e médicos-veterinários, foi utilizada a estatística analítica através do teste qui-quadrado de Pearson e do teste exato de Fisher, sendo p $<0,05$ o nível de significância considerado. Além deste, utilizou-se também o teste T de Student.

Para análise das prescriçóes, no que se refere à legibilidade, foram adotadas as seguintes categorias ${ }^{12}$ :

- Boa legibilidade: pode ser lida normalmente, sem problemas para entendimento da escrita;
- Escrita ilegível: é impossível o entendimento da escrita dos medicamentos prescritos;

- $\quad$ Escrita pouco legível: leva mais tempo para ser lida, ocasionando incerteza da compreensão total de todas as palavras, números, símbolos e abreviaturas.

Ainda no que se refere a este estudo, foram consideradas como erro de prescrição as receitas que se apresentaram pouco legíveis ou ilegíveis, com variáveis ausentes e incompletas.

\section{Resultados}

Foram analisadas 235 receitas de controle especial e notificaçōes de receita em uma farmácia comunitária, dentre as quais $67,7 \%$ (159) foram prescritas por cirurgiôes-dentistas e 32,3\% (76) por médicos-veterinários.

Do total de 76 prescriçóes realizadas por médicos-veterinários, 90,9\% (69) eram receitas de controle especial, o restante, notificaçóes de receita B1, sendo que nenhuma delas foi prescrita utilizando o modelo padrão de notificação de receita específico para uso veterinário.

Os requisitos legais obrigatórios de notificaçóes de receita, como identificação numérica da notificaçáo, identificação da gráfica, número de autorização da Vigilância Sanitária Municipal, número inicial e final do talonário, estavam presentes em $100 \%$ das notificaçóes de ambos os profissionais. Quanto à identificação da Unidade Federativa impressa na notificação de receita, $11,1 \%$ (1) das notificaçóes de receita B1 prescritas por cirurgião-dentista não apresentaram essa variável, ao passo que $100 \%$ das notificaçôes de médicos-veterinários tinham essa identificação.

Quanto à origem das prescriçóes, 97,5\% (155) das receitas de controle especial ou notificaçóes de receita de cirurgióes-dentistas e 100\% (76) das de médicos-veterinários foram provenientes do setor privado. $\mathrm{Na}$ Tabela 1 encontram-se os medicamentos controlados prescritos por médicos-veterinários, segundo a classificação ATC. Obteve-se o perfil de prescrição de medicamentos sob controle especial para esses profissionais, com maior predomínio de medicamentos antiepilépticos 75\% (57), destacando-se o fenobarbital como o fármaco mais prescrito dessa classe. Os hipnóticos/sedativos aparecem como segunda classe mais prescrita pelos médicos-veterinários, sendo o zolpidem o único medicamento receitado. 
Tabela 1: Distribuição percentual dos medicamentos controlados mais prevalentes prescritos por médicos-veterinários segundo a classificação ATC.

\begin{tabular}{lcc} 
Subgrupos Farmacológicos & $\begin{array}{c}(\%) \\
\text { N=76 }\end{array}$ & $\begin{array}{c}\text { ATC } \\
\text { Nível 3 }\end{array}$ \\
\hline Antiepilépticos & N03A \\
\hline $\begin{array}{l}\text { Fenobarbital } \\
\text { Outros }\end{array}$ & 52,6 & \\
\hline Hipnótico/Sedativo & 22,4 & N05C \\
\hline Zolpidem & 6,6 & \\
Outros* & 18,4 & \\
\hline
\end{tabular}

ATC: Anatomical Therapeutic Chemical. ${ }^{*}$ Inclui todos os subgrupos com $\mathrm{n}<5$. Fonte: Elaboração dos autores, 2016.

A classe ATC mais prescrita pelos cirurgióes-dentistas foi a do paracetamol em combinaçóes excluindo psicolépticos, sendo o paracetamol + codeína a única associação usada (Tabela 2).

Dentre os antiepilépticos, a pregabalina aparece como o medicamento mais prescrito.
Tabela 2: Distribuição percentual dos medicamentos controlados mais prevalentes prescritos por cirurgiões-dentistas segundo a classificação ATC.

\begin{tabular}{lcc}
$\begin{array}{l}\text { Subgrupos Farmacológicos } \\
\text { Antiepilépticos }\end{array}$ & $\begin{array}{c}\text { ATC Nível 3 e } \\
\text { Nível 5 }\end{array}$ \\
$\begin{array}{l}\text { Pregabalina } \\
\text { Outros }\end{array}$ & N03A \\
\hline $\begin{array}{l}\text { Ansiolítico } \\
\text { Bromazepam }\end{array}$ & 4,4 & N05C \\
\hline $\begin{array}{l}\text { Antidepressivo* } \\
\text { Sertralina }\end{array}$ & 3,8 & N06C \\
Venlafaxina & 1,2 & \\
Outros & 1,2 & \\
Paracetamol em combinaçóes & 1,9 & \\
excluindo psicolépticos* & & N02BE51 \\
\hline Paracetamol + codeína & 69,8 & \\
\hline Outros & 7,6 & \\
\hline
\end{tabular}

ATC: Anatomical Therapeutic Chemical ${ }^{*}$ Inclui todos os subgrupos com $\mathrm{n}<5$. ${ }^{* *}$ Classificação para a variável "Paracetamol em combinaçôes excluindo psicolépticos"

Fonte: Elaboração dos autores, 2016.

Tabela 3: Frequência dos dados analisados nas receitas de controle especial e notificações de receita em relação ao profissional prescritor em uma farmácia comunitária na Bahia.

\begin{tabular}{|c|c|c|c|}
\hline & Cirurgiáo dentista $(\mathrm{N}=159)$ & Médico-veterinário ( $\mathrm{N}=76)$ & Valor de $\mathbf{p}^{*}$ \\
\hline & Erros $(\%)$ & Erros $(\%)$ & \\
\hline Legibilidade & $20,6 \%$ & $12 \%$ & $<0,001$ \\
\hline Rasuras e emendas & $8,2 \%$ & $3,9 \%$ & 0,178 \\
\hline Abreviaturas & $75,5 \%$ & $78,9 \%$ & 0,399 \\
\hline Identificação completa do emitente & $53,4 \%$ & $23,7 \%$ & $<0,001$ \\
\hline Registro no conselho profissional & $57,2 \%$ & $31,6 \%$ & $<0,001$ \\
\hline Carimbo do prescritor & $0 \%$ & $1,3 \%$ & 0,323 \\
\hline Assinatura do prescritor & $0 \%$ & $0 \%$ & N/A \\
\hline Endereço e telefone do prescritor ou instituição & $0 \%$ & $2,6 \%$ & 0,104 \\
\hline $\mathrm{DCB}$ & $82,2 \%$ & $69,7 \%$ & $0,003^{*}$ \\
\hline Nome do paciente & $2,5 \%$ & N/A & N/A \\
\hline Endereço Paciente & $94,3 \%$ & N/A & N/A \\
\hline Identificação completa do animal & N/A & $96 \%$ & N/A \\
\hline Nome do animal & N/A & $7,9 \%$ & N/A \\
\hline Raça do animal & N/A & $98,7 \%$ & N/A \\
\hline Peso do animal & N/A & $98,7 \%$ & N/A \\
\hline Identificação do proprietário do animal (nome e endereço) & N/A & $98,9 \%$ & N/A \\
\hline Quantidade a ser dispensada & $15,1 \%$ & $10,5 \%$ & 0,168 \\
\hline Concentração do medicamento & $20,8 \%$ & $22,4 \%$ & 0,451 \\
\hline Forma farmacêutica & $4,4 \%$ & $3,9 \%$ & 0,587 \\
\hline Frequência de Administração & $0,6 \%$ & $0 \%$ & 0,677 \\
\hline Duração do tratamento & $45,9 \%$ & $57,9 \%$ & 0,057 \\
\hline Data de emissão & $4,4 \%$ & $0 \%$ & 0,107 \\
\hline Receituário correto & $0,6 \%$ & $0 \%$ & 0,747 \\
\hline
\end{tabular}

*Valores de $p$, através do teste qui-quadrado de Pearson, com diferença estatisticamente significante $p<0,005$. FA: frequência absoluta. N/A: não aplicável. DCB: Denominaçáo Comum Brasileira.

Fonte: Elaboração dos autores, 2016. 
No que se refere à quantidade de medicamentos controlados prescritos por receita, foi verificada a presença de dois medicamentos em $1,32 \%$ e $0,63 \%$ das prescriçóes de médico-veterinário e cirurgióes-dentistas, respectivamente. Todas as outras prescrições continham apenas um medicamento.

As receitas e notificaçóes de receita foram analisadas quanto à presença dos principais tipos de erros, tendo como parâmetro as legislaçóes vigentes acerca da adequada completude de receitas de medicamentos sob controle especial. A Tabela 3 evidencia as frequências das variáveis analisadas nas prescriçóes de cada profissional quanto à sua presença, ilegibilidade ou ausência.

As prescriçóes digitadas realizadas por cirurgióes-dentistas representaram um total de $17,6 \%$ (28), enquanto $82,4 \%$ (131) das prescriçōes desses profissionais foram manuscritas. Quantas às prescrições de médicos-veterinários, foi observada apenas uma receita digitada $(1,3 \%)(\mathrm{p}<0,001)$. Em se tratando de receitas manuscritas, a Tabela 3 mostra que houve uma maior porcentagem de prescriçôes legíveis para ambos os profissionais.

A presença de rasuras e emendas foi pouco frequente (8,2 e 3,9\%, respectivamente), em contrapartida, a utilização de abreviaturas ocorreu em 3/4 das prescriçóes de ambos os profissionais avaliados.

Nas prescriçóes de controle especial de duas vias e nas notificaçóes de receita dos cirurgióes-dentistas, a identificação completa do emitente (nome e endereço) e o número do registro do conselho profissional estiveram mais ausentes, numa comparaçáa com médicos-veterinários $(\mathrm{p}<0,001)$. Todas as prescriçôes dos cirurgiōes dentistas estavam completas para as variáveis carimbo e assinatura do prescritor. Já para os médicos-veterinários, o carimbo se fez presente em $98,7 \%$

No que se refere à identificação completa do paciente (nome + endereço), avaliada apenas para as prescrições de cirurgiōes dentistas, $95 \%$ das receitas estavam incompletas. $\mathrm{O}$ nome do paciente estava presente em $100 \%$ das receitas, mas o endereço estava ausente na grande maioria $(94,3 \%)$ delas. Quanto à identificação completa do animal pelos médicos-veterinários, também foi evidenciado que apenas $4 \%$ das prescriçôes estavam completas. Já a especificação de raça e peso do animal, assim como a presença da identificação do proprietário, só constou em 1,3\% das receitas.

$\mathrm{Na}$ grande maioria das prescriçôes de cirurgióes-dentistas e médicos-veterinários (86,8 e 69,7, respectivamente) os medicamentos não estavam descritos conforme a Denominação Comum Brasileira (DCB) $(\mathrm{p}<0,001)$.

Com relação aos dados referentes ao medicamento, destaca-se a ausência da duração do tratamento para ambos os profissionais. Observou-se que a grande maioria
(99,3 e 100\%) das prescriçôes foi realizada em receituário adequado, conforme modelo descrito na legislação.

Foram observados cerca de 1.529 erros entre os profissionais prescritores avaliados, com destaque para o número de erros para os médicos-veterinários, Tabela 4.

Tabela 4: Média de erros presentes em receitas e notificações de receita de medicamentos sob controle especial, de acordo com o profissional prescritor, aviadas em uma farmácia comunitária na Bahia.

\begin{tabular}{lcccc} 
Variáveis & Média & DP \pm & IC $_{95 \%}$ & Valor $\mathbf{p}^{*}$ \\
$\begin{array}{l}\text { Prescritor } \\
\text { Dentista }\end{array}$ & 5,49 & $\pm 2,0$ & $(5,18-5,80)$ & \\
$\quad$ Veterinário & 8,45 & $\pm 2,0$ & $(8,00-8,90)$ & $<0,001$ \\
\hline
\end{tabular}

DP: desvio padrão. IC: intervalo de confiança. ${ }^{*}$ Teste T de Student Fonte: Elaboração dos autores, 2016.

\section{Discussão}

Tanto no campo da odontologia quanto no âmbito veterinário, no que tange à revisão realizada pelos autores, pouco se encontrou sobre a temática de avaliação de erros em prescriçóes sujeitas a controle especial prescritas pelos profissionais. Mostra-se importante à realização de novos estudos que analisem a prática prescricional, para que os erros encontrados na observância das normas de prescrição sejam minimizados.

Neste estudo, verificou-se que para o uso veterinário os anticonvulsivantes, em especial o fenobarbital, foram os mais prescritos por essa classe profissional. Esse medicamento é indicado para o controle de convulsões focais e generalizadas e apresenta um baixo custo, representando uma alternativa terapêutica mais acessível ${ }^{13}$. O zolpidem, pertencente à classe dos hipnóticos e sedativos, é indicado, tanto em cães como em gatos, para reduzir a ansiedade geral e o medo, além disso, também atua como relaxante muscular de ação central, permitindo uso como pré-anestésico ${ }^{13}$.

De acordo com a portaria que regula o ato de prescrever medicamentos sujeitos a controle especial (Portaria no 344/98 SVS/MS), o médico-veterinário detém tal competência, desde que os medicamentos sejam para uso veterinário, e inexiste qualquer lista taxativa de medicamentos permitidos, não havendo limitação legal da prescrição ${ }^{3}$.

A medicina veterinária tem como alternativa a prescrição off-label de medicamentos para uso humano para tratar estados de doença animal, justificada pelo fato de essa classe profissional ainda náo possuir uma grande variedade de produtos aprovados ${ }^{14}$.

Já para o grupo dos cirurgióes-dentistas, a prescrição da associação codeína e paracetamol superou todas 
as demais. Dado semelhante foi obtido por Marmitt ${ }^{15}$, que verificou os medicamentos mais prescritos por cirurgióes-dentistas vinculados a uma faculdade de odontologia, sendo a prescriçáo do paracetamol a mais frequente. A eficácia e segurança dessa associação justifica sua maior utilização no tratamento da dor $^{16}$. Em um estudo comparativo a respeito da eficácia do paracetamol isolado versus a sua associação com a codeína (vendida com retenção de receita de controle especial branca duas vias), em pacientes submetidos à exodontia de dentes retidos, foi relatada uma superioridade da referida combinação, de ação analgésica, no controle da dor no pós-operatório ${ }^{17}$.

Os antiepilépticos apareceram como a segunda classe mais prescrita, sendo referidos na literatura como alternativa no tratamento das dores neurogênicas, como as provenientes das disfunções da articulação temporomandibular e do nervo trigêmeo ${ }^{15}$. Esta última, apesar de não ser tratado pelo profissional odontólogo muitas vezes é confundida com alguma disfunção de caráter odontogênico, levando o paciente a buscar atendimento inicial por um cirurgião-dentista ${ }^{18}$.

Ademais, em menor proporção, os antidepressivos também foram objeto de prescrição. Hersh et al. ${ }^{19}$ relatou, do mesmo modo que os antiepilépticos, a aplicabilidade dos antidepressivos no controle da dor nos transtornos da articulação temporomandibular. De forma equivalente, foi indicado o uso do diazepam, pertencente ao grupo dos ansiolíticos, que teve, por $\mathrm{Melo}^{20}$, sua efetividade demonstrada no controle das dores nos distúrbios orofaciais. Ainda no âmbito odontológico, o estresse temporário, muitas vezes provocado por um procedimento odontológico cirúrgico, pode originar uma ansiedade aguda, situação em que essa classe de medicamentos também está indicada ${ }^{21}$. As normas vigentes deixam estabelecida a prerrogativa de possibilidade de o cirurgião-dentista prescrever medicamentos, sem restrição, embasado nos conhecimentos odontológicos que melhor atendam a demanda do paciente no sentido de curar, diminuir ou estabilizar a enfermidade diagnosticada ${ }^{3,22}$. Outrossim, é fundamental o conhecimento da farmacologia e de suas relaçóes com a prescriçáo, para o correto manejo dos pacientes, de forma que o uso racional de medicamentos, nos quesitos segurança, efetividade e prevenção de erros, seja maximizado ${ }^{23}$.

Os percentuais encontrados para a legibilidade foram superiores aos valores evidenciados no estudo de Mastroianni ${ }^{24}$, que analisou 1.335 prescriçóes médicas, das quais apenas 58,8\% estavam em letra legível. Conforme argumenta $\mathrm{Mendes}^{25}$, a não compreensão da proposta terapêutica inscrita na receita pode culminar em complicaçóes e agravo do estado de saúde do paciente. As receitas ilegíveis, ainda que presentes, representaram a minoria em nosso estudo, o que evidencia o compromisso das classes profissionais em análise para com a comunicaçáo essencial entre os profissionais prescritor e dispensador, logo, facilitando a compressáo do paciente, cuidador e dono (para os animais) acerca da utilizaçáo do medicamento.

Os dados referentes ao profissional prescritor, no grupo dos cirurgióes-dentistas, indicou uma maioria de receitas com dados ausentes nas variáveis "Identificação completa do emitente" e "Número do registro no conselho profissional" nos campos adequados, conforme modelo padrão da legislação. Essas omissóes dificultam ou inviabilizam o acesso e comunicação por parte de usuários e dispensadores aos profissionais responsáveis ${ }^{7}$. Constatou-se também nos resultados que o endereço/ telefone do prescritor ou do estabelecimento de saúde estava presente em todas as receitas e notificações de receita de controle especial prescritas por cirurgióes-dentistas, o que facilita a localização e o contato com o prescritor em caso de dúvidas quanto ao tratamento.

No que concerne às informaçóes do paciente, é sabido que as prescriçôes constituem um instrumento individual, requerendo informaçóes singulares sobre quem é o destinatário da conduta indicada, sendo elas condição necessária e indispensável ${ }^{7}$. Contrapondo-se a este requisito, este estudo apontou percentuais elevados de receitas com ausência de identificação completa do paciente no grupo dos cirurgióes-dentistas. Com relação à ausência da variável endereço, apesar de estar relacionada à não interferência clínica, ela repercute na dificuldade de uma eventual necessidade de contato posterior da farmácia com o paciente $e^{4,7,24,25}$.

Em se tratando das informaçóes fornecidas pelo médico-veterinário sobre a identificação completa do animal, foi verificado que houve uma grande ocorrência de prescrições incompletas, em que apenas o nome do animal foi preenchido. A descriçấo da raça, peso do animal, nome e endereço completo do proprietário, como preconizado pela Portaria no 344/98 SVS/MS ${ }^{5}$, em seu anexo XI, modelo de talonário "B" para uso veterinário contemplando aos demais receituários, estiveram preponderantemente ausentes. Tendo em vista o desfecho terapêutico esperado, deve-se considerar a importância desses dados, visto que o conhecimento da raça e o peso do animal interferem diretamente na dose a ser administrada, o que remete a ajustes da posologia-padrão, que inclui a dose, para que se faça correção de forma individualizada ${ }^{26}$, constituindo em um dos critérios para o uso racional de medicamentos.

Fica clara na referida legislação a obrigatoriedade do nome completo e do endereço do proprietário, conforme o artigo 55 da Portaria 344/98. As omissóes dessas informaçốes ocasionam a recusa da receita, prolongando 
o início do tratamento do animal, visto que se faz necessária a volta ao médico-veterinário para corrigi-la. Como já dito anteriormente, a ausência desses dados impossibilita um contato posterior com o cuidador do animal, em caso de uma eventual necessidade por parte da farmácia ou algum órgão fiscalizador.

Outro fator verificado neste estudo foi a utilização da $\mathrm{DCB}$, que foi pouco aplicada na população analisada. A indústria farmacêutica faz-se muito presente na promoção dos nomes comerciais das formulaçôes por meio de propaganda, estimulando a prescrição pelo nome de marca. Apesar de náo obrigatória nos serviços privados, é recomendável a implementação da DCB por parte dos profissionais prescritores, uma vez que a utilização dessa denominação promove uma racionalização no uso de medicamentos, visto que ela melhora a prática da prescrição e dispensação, permitindo que o paciente possa obter um medicamento de preço acessível, que tem a mesma segurança, qualidade e eficácia do medicamento referência ${ }^{27}$.

Considerando as diferenças entre os estudos pôde-se verificar que a média de erros por receitas de controle especial e notificaçóes de receita neste estudo foi superior ao encontrado por Guzatto e Bueno ${ }^{28}$ em estudo realizado numa farmácia de uma unidade básica de saúde do município de Porto Alegre, no qual, houve 5,3 $( \pm 2)$ de média de erros encontrados por prescriçáo médicas. A existência de erros pode gerar dúvidas, levando ao comprometimento da terapêutica a ser implementada. Mesmo que grande parte dos medicamentos ofereça segurança no uso, as falhas nas prescriçōes podem ocasionar riscos graves ao usuário. A existência de incorreções, rasuras e emendas nas receitas podem levar a uma não dispensação da prescrição, uma vez que toda informaçáo necessária ao uso adequado do medicamento deve estar presente ${ }^{29}$. Esse dado remete ao não cumprimento das normativas prescricionais por parte do farmacêutico, visto que ele é o profissional responsável pela avaliação das receitas e notificaçóes de receita do ponto de vista técnico, e é de conhecimento dele que apenas podem ser aviadas as receitas que estejam de acordo com as informaçôes exigidas pela legislação vigente ${ }^{3}$.

Prescrições em conformidade com as exigências estabelecidas pelas legislaçóes podem evitar a ocorrência de erros de medicação, assegurando uma farmacoterapia com maior efetividade e segurança para o paciente, salientando a relevância de uma prescrição de qualidade ${ }^{29}$.

$\mathrm{O}$ estudo apresenta limitaçóes, pois foi realizado em apenas um estabelecimento de saúde podendo não ser representativo de outras realidades. No entanto, a experiência profissional dos autores em ambientes diversos sugere que a realidade evidenciada é bastante comum. A análise foi embasada apenas na prescrição (receita de controle especial branca de duas vias e notificaçáo de receita), não sendo possível a avaliação de erros de prescrição clinicamente significativos. Além disto, a maioria das prescriçóes foi oriunda de profissionais que atendem em consultórios privados, o que pode não representar o universo de prescritores dentistas e médicos-veterinários que atendem ao setor público também.

\section{Conclusão}

Pode-se verificar neste estudo um grande número de erros em prescrições realizadas por cirurgióes-dentistas e médicos-veterinários por não apresentarem a completude de itens obrigatórios legalmente requisitados pela legislação. O preenchimento completo e legível de todos os dados em uma prescrição se faz necessário para evitar erros de medicação, eventos adversos ou qualquer outro problema relacionado à terapia medicamentosa.

É importante também citar que no Brasil ainda não existem legislaçóes que definam os medicamentos para um arsenal terapêutico racional à odontologia e medicina veterinária. É recomendável melhor formaçáo dos prescritores da área objeto de estudo, uma melhor comunicação do prescritor com o farmacêutico e o estabelecimento de bases racionais para a prescrição de profissionais cirurgiốes dentistas e médicos-veterinários.

\section{Referências}

1. Terada ASSD, Ortiz AG, Leite NLP, Scandiuzzi RJ, Silva RHA. Conhecimento dos cirurgiôes-dentistas do município de Ribeirão Preto sobre prescrição medicamentosa. Arq Ciênc Saúde. 2012;19(4):123-7.

2. Arrais PSD, Barreto ML, Coelho HLL. Aspectos dos processos de prescrição e dispensação de medicamentos na percepção do paciente: estudo de base populacional em Fortaleza, Ceará, Brasil. Cad Saúde Pública. 2007;23(4):927-37.

3. Agência Nacional de Vigilância Sanitária (Brasil). Portaria no 344, de 12 de maio de 1998. Aprova o Regulamento Técnico sobre substâncias e medicamentos sujeitos a controle especial. Brasília, DF; 1998.

4. Mota IVR, Nascimento LES, Cardoso RA, Lemos LB, Lemos GS. Medicamentos sob controle especial: uma análise dos erros de medicação e indicadores de prescrição. Rev Eletrônica Farm. 2016;13(1):45-54.

5. Silva ERB, Bandeira VAC, Oliveira KR. Avaliação das prescriçóes dispensadas em uma farmácia comunitária no município de São Luiz Gonzaga, RS. Rev Ciênc Farm Básica. 2012;33(2):255-81.

6. Melo GC, Sousa LMG, Bispo FCL, Firmo WCA. Conhecimento de clientes e análise de prescriçóes 
médicas de substância da lista C1 de uma drogaria do município de Santa Inês, Maranhão, Brasil. InterfacEHS. 2015;10(2):83-94.

7. Souza SSS, Pinheiro MTRS, Almeida PHRF, Lemos LB, Lemos GS. Sibutramina: falhas e incompletude de documentos na prescrição e dispensação. Rev Aten Saúde. 2017;15(51):23-33.

8. Matta SR, Miranda ES, Osorio-de-Castro CGS. Prescrição e dispensação de medicamentos psicoativos nos instrumentos normativos da regulação sanitária brasileira: implicaçóes para o uso racional de medicamentos. Rev Bras Farm. 2011;92(1):33-41.

9. Rosa MB, Perini E, Anacleto TA, Neiva HM, Bogutchi T. Erros na prescrição hospitalar de medicamentos potencialmente perigosos. Rev Saúde Pública. 2009;43(3):490-8.

10. Batista SRS, Andrade RO, Oliveira FA, Carmo GM, Lopes, FM. Análise das qualidades das prescriçôes médicas dispensadas em drogarias do interior de Goiás: um risco à saúde do paciente. Ens Ciênc. 2014;16(6):91-103.

11. Noto AR, Carlini EA, Mastroianni PC, Alves VC, Galduróz JCF, Kuroiwa W, et al. Análise da prescrição e dispensação de medicamentos psicotrópicos em dois municípios do Estado de São Paulo. Rev Bras Psiquiatr. 2012;24(2):68-73.

12. Lima TAM, Gouveia MIS, Pereira LLV, Godoy MF. Erros de prescriçôes médicas em drogaria. Infarma. 2016;28(1):16-21

13. Spinosa HS, Górniak SL, Bernardi MM. Farmacologia aplicada à Medicina Veterinária. 5a ed. Rio de Janeiro: Guanabara Koogan; 2011.

14. Ceresia ML, Fasser CE, Rush JE, Scheife RT, Orcutt CJ, Michalski DL, et al. The role and education of the veterinary pharmacist. Am J Pharm Educ. 2009;73(1):1-9.

15. Marmitt GF. Prescrição de medicamentos para tratamento da dor por cirurgióes dentistas vinculados a uma faculdade de Odontologia [monografia]. Porto Alegre (RS): Universidade Federal do Rio Grande do Sul; 2010 [citado em 2016 set 5]. Disponível em: <https://goo.gl/jcheVC>.

16. Toms L, et al. Single dose oral paracetamol (acetaminophen) with codeine for postoperative pain in adults. Cochrane Database Syst Rev. 2009;(1):CD001547.

17. Santini MF. Comparação entre duas associaçóes de analgésicos náo opioides e opioides no controle dador do abscesso dentoalveolar agudo em evoluçáo: um ensaio clinico randomizado [doutorado]. Porto Alegre: Universidade Federal do Rio Grande do Sul; 2015 [citado em 2017 jun 5]. Disponível em: <https://goo.gl/5WTE6m>.

18. Borbolato RM, Ambiel CR. Neuralgia do trigêmeo: aspectos importantes na clínica odontológica. Saúde Pesqui. 2009;2(2):201-8.

19. Hersh EV, Balasubramaniam R, Andres P. Pharmacologic management of temporomandibular disorders. Oral Maxillofacial Surg Clin North Am. 2008;20(2):197-210.

20. Melo GM. Terapia farmacológica em disfunçôes temporomandibulares: uma breve revisão. Rev Dent On Line. 2011;10(21):35-40.

21. Oliveira MC, Aleixo RQ, Rodrigues MTV. Uso de benzodiazepínicos em cirurgia bucomaxilofacial. Saber Cient. 2010;1(1):53-67.

22. Costa SANL, Castro RD, Oliveira JA, Cardoso ANS. Prescrição medicamentosa: análise sobre o conhecimento dos futuros cirurgióes-dentistas. Rev Bras Odontol. 2013;70(2):172-7.

23. Souza GFM, Silva KFFB, Brito ARM. Prescrição medicamentosa em Odontologia: normas e condutas. Cad Saúde Colet. 2011;19(2):208-14

24. Mastroianni PC. Análise dos aspectos legais das prescriçôes de medicamentos. Rev Ciênc Farm Básica e Apl. 2009;30(2):173-76

25. Mendes VZ, Aragão CCV, Sabino W. Análise das características de legibilidade da prescrição de medicamentos e o perfil farmacoterapêutico de pacientes hipertensos. Rev Aten Saúde. 2015;13(44):46-51

26. Nicoletti MA, Fukushima AR. Seguimento farmacoterapêutico direcionado aos animais domésticos: seria viável? Infarma. 2014;26(4):246-50.

27. Weber D, Bueno CS, Oliveira KR. Análise das prescriçôes medicamentosas de um hospital de pequeno porte do noroeste do estado do Rio Grande do Sul. Rev Ciênc Farm Básica Apl. 2012;33(1):139-45

28. Guzatto P, Bueno D. Análise de prescriçóes medicamentosas dispensadas na farmácia de uma unidade básica de saúde de Porto Alegre, RS. Rev HCPA. 2007;27(3):20-6.

29. Azevedo LS, Pereira LJ, Zangerônimo MG, Sousa RV, Murgas LDS, Marques LS, et al. Avaliação da adequação legal de receitas e notificaçóes de receita de medicamentos sujeitos a controle especial dos setores públicos e privados. Rev Ciênc Farm Básica Apl. 2011;32(3):401-17.

\section{Como citar este artigo:}

Cardoso RA, Mota IVR, Lemos LB, Almeida PHRF, Rosa MB, Lemos GS. Erros em receitas de controle especial e notificaçóes de receita prescritas por profissionais não médicos.. Rev. Aten. Saúde. 2018;16(55):42-49. 